\title{
Implementation of Informed Consent in Complementary \& Alternative Medicine (Cam) in Homeopathy Services by Ahmadiyya Congregation Practices in Yogyakarta and Jakarta
}

\begin{abstract}
Putri Ratnasari $\mathbf{D}^{1 *}$, Siwi Padmawati $\mathbf{R}^{1}$ and Kusmaryanto $\mathrm{CB}^{2}$
${ }^{1}$ Department in Bioethics, the Graduate School of Gadjah Mada University, Indonesia

${ }^{2}$ Department in Divinity Philosophy, Sanata Dharma University, Indonesia
\end{abstract}

*Corresponding author: Desy Putri Ratnasari, Department in Bioethics at the Graduate School of Gadjah Mada University, Indonesia, Email: desy.putri.ratnasari@mail.ugm.ac.id

\section{Review Article \\ Volume 4 Issue 3}

Received Date: July 28, 2021

Published Date: September 06, 2021

DOI: $10.23880 /$ abca-16000197

\section{Abstract}

Informed consent is the consent given to a patient for a medical action after obtaining all important information about the nature and consequences of the action. Procedures regarding the method and content of informed consent still need to be analyzed to provide protection for doctors, patients and related institutions. The purpose of this study is to discuss more deeply about the method and content of informed consent in homeopathic services by practitioners of the Ahmadiyya congregation. This study used a qualitative descriptive method with a total of 20 participants consisting of homeopaths, patients, and staff of the National Homeopathy Department which was conducted through in- depth interviews using purposive sampling and then data is processed using coding and presented descriptively. Homeopaths more often use informed consent oral. The elements of informed consent:

- A good way of delivering information is conditioned according to the background and psychological condition of the patient.

- Correct in the delivery of homeopathy (how to reveal the patient's diagnosis, alternative goals of action, risks, prognosis where every homeopath never promises a cure to the patient and completely free financing except for homeopaths that have independent clinics.

- Complete information the factors that influence the use of homeopathy are dissatisfaction in $34 \%$ of patients; need for personal control in $16 \%$ of patients; and philosophical congruence in $50 \%$ of patients. The application of informed consent is not just giving a signature, but the essence of informed consent is explanation of the information followed by informed consent either in oral or written form so that the patient can make decisions and can be accounted for. More comprehensive education, policies and in-depth socialization of informed consent are urgently needed for practitioners.

Keywords: Informed Consent; Homeopathy; Ahmadiyya Muslim Congregation

\section{Introduction}

The principle of informed consent is made to respect the dignity of a free and autonomous human being where every human being is free to determine for himself what to do or not to do by refusing to give consent to certain medical actions based on knowledge sufficient information about the advantages, disadvantages and associated risks. According to Nasichin $\mathrm{M}$, et al. [1] that informed consent means an agreement or patient consent for medical efforts that will be 
carried out by the doctor against him (the patient) after the patient has received information from the doctor regarding medical efforts that can be taken to help himself (the patient) accompanied by information about the possible risks. All information should be given and explained to the patients or their families, according Guwandi as quoted Titisari NW, et al. [2] is the inherent risk (inherent) in patients in the medical treatment; the presence of possible side effects; alternative if there is a course of action other than the proposed one; What might happen if action is not taken. Another problem that often arises in the application of informed consent is how well the patient understands the contents of the informed consent given, because it is not uncommon for patients to make decisions with a lack of understanding of the contents of the form informed consent. Problems related to the patient's ability to understand the contents of the informed consent include differences in education level, physical and mental limitations and the content of the form informed consent itself. In complementary \& alternative medicine, and also required informed consent.

According to the Patient Safety Curriculum Guide WHO (2011), health interventions have an element of uncertainty as to whether or not they will improve patient health. Individuals have the right to receive useful information about the quality of service they receive, especially if the service is an invasive intervention. If the patient consents, then family members should also be involved in the exchange of information. Informed consent is the free consent given to a patient about a medical action after he or she has obtained all important information about the nature and consequences of the action. The principle of informed consent is made to respect the dignity of free and autonomous human beings, that is, every human being is free to decide for himself what will be made or what will not be made Ratman D, et al. [3]. Humans have dignity not because they were given by someone or by the state or society, but because humans are dignified because they are humans. From him-self, humans are valuable so that they do not need other things or other external factors to make humans dignified as humans Kusmaryanto CB, et al. [4]. According to Beauchamp TL, et al. [5], a person's autonomy refers to 'self-governance' which means freedom from intervention, control and limitations from others, for example inadequate understanding that prevents his choice. The principle of respect for autonomy can be expressed as a negative obligation and a positive obligation. Autonomous actions should not be subject to control others; this positive obligation principle requires respectful treatment in disclosing information and encouraging autonomous decision making. Therefore, it is important for a doctor or practitioner who will perform a medical procedure to provide a complete explanation using language that is easily understood by the patient.
According to the National Center for Complementary and Alternative Medicine Odette P, et al. [6], complementary medicine refers to practices used in conjunction with conventional medicine, for example acupuncture is used in conjunction with conventional pain relievers. Alternative medicine includes practices that are used in place of conventional practices, whereas integrated medicine is defined as conventional medicine combined with CAM practices that are safe and show some evidence of efficacy. CAM includes all practices and ideas defined by its users as the prevention or treatment of disease or to promote health and well-being. The boundaries within CAM and between the CAM domain and the dominant system are not always clear.

In Indonesia, many sufferers finally come for treatment at alternative medicine clinics and have consulted with one or more traditional healers or healers. There are three assumptions according to $\mathrm{Pal} \mathrm{SK}$, et al. [7] that can explain the factors of using CAM treatment, namely:

Dissatisfaction is that patients are dissatisfied with conventional treatment because it is ineffective, causes adverse side effects, or is considered impersonal, too technology-oriented, and/or too expensive.

$>$ Need for personal control, i.e. patients seek alternative therapy because they see the therapy as less/not authoritarian by prioritizing personal autonomy and control over their decisions and health conditions (patients).

$>$ Philosophical congruence, namely alternative therapy is more attractive because it is considered more in accordance with patient values, world-view, spiritual/ religious philosophy or beliefs about the nature and meaning of health of a disease.

According to WHO (2009) [8], the term homeopathy comes from the Greek word ö $\mu o t o \varsigma$ (hómoios: similar) and

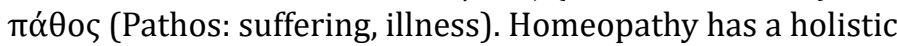
healing approach with the main principle being "like cures like" (in Latin: similar care).

Homeopathy is a system of medicine that works with the immune system to achieve natural healing. This treatment has the principle of treating a person as a whole (holistic) which includes physical, emotional and mental. The basic theory of homeopathy is that sick people can be cured by using the reflected effect of substances that produce symptoms of illness in healthy people. Homeopathy is prepared by adding a lot of water in a substance, then shaking it and taking some water, adding it to a lot of water, shaking it and this process is repeated up to 200 times in some remedies. Hahnmemann says that this will bring out the "healing power of medicine" Rachma E, et al. [9]. 
According to Setiawan L, et al. [10] in "30 Alternative Medicine", Dr. Jenny Bashiruddin Pontoj explained that making homeopathic medicines can be done by everyone, because the ingredients are easy to get and the method of making it is also easy. For example, basic ingredients from plants that are still rough are cut into small pieces, for basic mineral ingredients to be mashed; basic ingredients from animals are cut into pieces depending on the type. Then the material is immersed in $90 \%$ alcohol then shaken vigorously and tightly closed. This solution is allowed to stand for two to four weeks and then filtered into bottles. This solution is called 'mother tincture' usually abbreviated as Q. From Q can be made drugs with high or low potency, after dripping with sugar medium in the form of granules. In homeopathy known two kinds of potency depending on the amount of alcohol mixed. The higher the dilution and agitation process, the smaller the molecule, so that the healing effect increases.

The Ahmadiyya Congregation is a religious group that follows the teachings and instructions of Mirza Ghulam Ahmad al-Qodiyani. This congregation was founded on March 23, 1889, led by Mirza Ghulam Ahmad who was born in Qodiyan, India on February 13, 1835 and died on May 26, 1908 Ahmad HMBM, et al. [11]. Mirza Ghulam Ahmad started this movement inspired by the teachings and messages of Islam which are full of virtue, peace and brotherhood. Within a century, the Ahmadiyya congregation had spread to all corners of the world. This congregation continues to try to expand its influence, building Islam through social projects, educational institutions, health services, publishing Islamic literature and building mosques despite obstacles in several countries. According to Mirza Ghulam Ahmad, the Ahmadiyya Congregation movement was born based on divine demands with the aim of rejuvenating Islamic morals and spiritual values Suryawan MA, et al. [12].

On the advice of the Fourth Ahmadiyya Caliph, Mirza Tahir Ahmad while visiting Indonesia in 2000, homeopathic remedies were applied and this treatment is free for the people of Indonesia until now. In one of the Ahmadiyya beliefs, an Ahmadi is said to be successful if he has learned to sacrifice for the sake of others. This principle of giving and sacrificing is not only for the Ahmadiyya congregation but also for society in general Santoso I, et al. [13].

Researchers are interested in conducting research on alternative complementary homeopathic medicine conducted by practitioners of the Ahmadiyya Congregation in Indonesia because the Ahmadiyya Congregation has made the homeopathic treatment system one of many humanitarian programs as well as a form of expression of spirituality. The National Homeopathy Department is the official institution of the Indonesian Ahmadiyya Congregation which provides complementary \& alternative medicine services homeopathy. Therefore, researchers are interested in observing how the implementation of the method and content of informed consent in homeopathic services is carried out by the Ahmadiyya Congregation practitioners in the Yogyakarta and Jakarta.

\section{Objective}

This study aims to find out and understand the contents of the implementation of the way and informed consent (informed consent) in complementary and alternative medicine (CAM) in the homeopathic practitioner services Ahmadiyya either a background as medical and non-medical personnel. The next goal is to see firsthand the complementary \& alternative medicine (CAM) homeopathic treatment services of the Ahmadiyya Congregation and find out the appreciation of patients about the services homeopathy Treatment of the Ahmadiyya Congregation.

\section{Methods}

Research designs this research method is descriptive qualitative to find out or describe the reality of the events studied so as to facilitate obtaining data objective on the application of informed consent for homeopathy treatment services in the Ahmadiyya with data collection techniques in the form of observation data followed by in-depth interviews for 45-90 minutes.

\section{Data Collection}

The number of participants in this study was 20 out of a total of 40 participants, making it approximately $50 \%$ of the total Ahmadiyya homeopath in Yogyakarta and Jakarta. The inclusion criteria consisted of 13 main homeopathic practitioners from the Ahmadiyya who had medical backgrounds (doctors) and non-medical backgrounds (midwives, clinical psychologists, pharmacologists, preachers and members of the Ahmadiyya) and had attended homeopathy certificate training and homeopathy independent practice at least 1 year and 7 participants involving a variety of Ahmadiyya patients and nonAhmadiyya patients who have used homeopathy treatments at least 2 times with a span of time in the last 1 year, as well as directors and staff of the National Homeopathy Department. Each participant was interviewed by researchers with face-to-face interviews for the Yogyakarta area and online interviews using Zoom Meeting for the Jakarta area for 45-60 minutes and the interview recordings were then converted into transcripts. 


\section{Instrument}

The research using instruments that are open questions (open question) to determine the application of informed consent to service of homeopathic medicines by medical practitioners and non-medical personnel; the views of the patient and/or the patient's family on the method and content of informed consent for homeopathic services; as well as perceptions of the management of informed consent for homeopathic services by the National Homeopathy Department.

\section{Data Analysis}

This qualitative descriptive research after the transcript was completed and then validated by doing member checking. The transcripts were analyzed according to the theme by the researcher as well as the study participants using codes by Open Code software. Researchers and participants conducted the analysis in separate places and there was no intervention from anyone. The next stage of analysis is a combined analysis by way of integration and triangulation.

\section{The Ethical Aspect}

This research has been approved by the Research Ethics Committee of the Faculty of Medicine, Public Health and Nursing, Gadjah Mada University with letter number KE/ FK/0564/EC/2021 dated 02 June 2021 and permission for the research location issued by the Ahmadiyya Congregation dated 24 May 2021. Data collection is carried out during the period June 2021. All qualitative data has been stored and can only be known and accessed by researchers. Names of interview participants were not included in reports or publications of this study.

\section{Results and Discussion}

\section{Overview of Research}

The Ahmadiyya Muslim Congregation is an Islamic revival movement, international in scale, dynamic and rapidly growing. Founded in 1889, today the Ahmadiyya has spread to 210 countries with followers in the tens of millions. The Ahmadiyya Muslim Community is the only Islamic organization that believes that the long-awaited Messiah has arrived in the form of Mirza Ghulam Ahmad as (1835-1908). This research was conducted in two provinces where the Ahmadiyya Congregation is located in Yogyakarta, precisely in Pucanganom Village, Rongkop, and Asih Sasama Clinic, Saptosari, Gunung Kidul Regency, while in Jakarta, namely the National Homeopathy Department, precisely on Jalan Balikpapan I/10 Central Jakarta. The study participants were 20 people consisting of 10 Yogyakarta's participants (1 doctor, 1 midwife and 2 preachers from the Ahmadiyya; 3 patients from the Ahmadiyya and 3 patients from nonAhmadiyya); and 10 participants in Jakarta with descriptions of homeopathic practitioners who have medical and nonmedical backgrounds; director and secretary of the National Department of Homeopathy. Researchers conducted indepth interviews for 45-90 minutes face to face interview for the DIY area and online interviews for the DKI Jakarta area which were recorded as primary data (Table 1 ).

\begin{tabular}{|c|c|}
\hline Characteristics of Participants & Frequency \\
\hline Age & 10 \\
\hline 45 & 10 \\
\hline Religion & 20 \\
\hline Islam & 11 \\
\hline Gender & 9 \\
\hline Male & 3 \\
\hline Female & 3 \\
\hline $\begin{array}{c}\text { Membership status of the Ahmadiyya Community } \\
\text { Patient }\end{array}$ \\
\hline No & 4 \\
\hline \multicolumn{2}{|c|}{ Participant } \\
\hline $\begin{array}{c}\text { Doctor licensed homeopath } \\
\text { physician) }\end{array}$ \\
\hline Mubalig \\
\hline $\begin{array}{c}\text { Management of the National } \\
\text { Homeopathy Department }\end{array}$ \\
\hline Praner licensed homeopath (non- \\
\hline
\end{tabular}

Table 1: Characteristics of Participants.

In homeopathic medicine, the patient has a history of disease that is categorized from acute to chronic disease chronic. Chronic disease is a disease with permanent characteristics, causing disability in the sufferer, and to cure it the patient needs to take care for a long period of time. Generally, homeopathy treat mild diseases (common illness), mild moderate and acute. Some patients who are familiar with homeopathy become the primary treatment for patients of the Ahmadiyya congregation and have never complained about the side effects of homeopathy.

"Alhamdulillah, yes, I rarely get sick, maybe it's just the flu, I cough, then I happened to sprain my leg, I asked for homeopathic medicine. Immediately tried homeopathic remedies and it immediately felt less pain." 
(P15, female, 45 years old, Ahmadiyya patient, self-employed). Meanwhile, non-Ahmadiyya patients generally already suffer from chronic diseases. Patients know homeopathic remedies from local residents. According to them, homeopathy is more effective in treating the disease than conventional medical drugs. The patient also does not feel any side effects from homeopathic remedies. The patient's decision in choosing homeopathic treatment is because they are not satisfied with conventional medical treatment, the distance is long and the cost is expensive.

"There is a narrowing of the kidney channel and swelling of the kidney stone, and the muscles are all sore. "Because I've been to smart people like shamans like that, it's not reduced, but the complaints are still the same muscle pain. Then there are neighbors who say, have been there to Mr. Mubalig's place, he said there is treatment like therapy like that. Yes, I took the initiative to go there, it turns out that there are changes too, but little by little, just keep going." (P18, male, 38 years old, non-Ahmadiyya patient, and self- employed).

\section{Perspective of Informed Consent according to Practitioners, Patients and management of the Department National Homeopathy (DHN)}

In this study, it was found that there were still many who did not understand the term "informed consent". Medical personnel define informed consent as the delivery of information about medical care or services accompanied by written or oral consent. Doctors in the Ahmadiyya can become homeopathic practitioners because apart from socialization and homeopathy counseling from the caliph, doctors are also interested in learning homeopathy as first aid for minor ailments to treat their families. The implementation of informed consent in homeopathic services according to the doctors must be in accordance with the procedure even though it is given to the closest person.

"Indeed, people in the village are afraid to sign. But I said that the signature doesn't mean this is weird, I explain this as a doctor; I provide therapy to be clear, and where, how, and for what. Don't just give. I also have basic of his, and then I show my certificate college and everything, eventually the patient understands. So the signature of the mother (patient) is my responsibility, if later the mother (patient) is asked outside, someone asks, what medicine is it, from whom, as if I forced the mother, I never did." (P13, male, 34 years old, doctor)

Meanwhile, non-medical personnel (non-doctors) and patients interpret informed consent as a blank sheet that must be signed. However, the implementation of informed consent in homeopathic services in the Ahmadiyya congregation has been carried out properly, properly and completely informed. For preachers who have taken special education for preachers, there is homeopathic material for one semester which is intended to prepare for community service. Then, practitioners also take part in a 100-hour training provided by the National Homeopathy Department and/or self-study in Singapore or the UK to earn an academic degree in homeopathy.

"If you study it, you could say it's like education or the term is homeopathic classes that I actively participated in when I was educated at the final level of Jami'ah, where the preachers were equipped with knowledge of this homeopathic system of medicine that was around 2007, I was there for 6 months studying homeopathy officially. As long as I haven't received the education, I still help the preacher, analyze patients, give prescriptions, help prepare medicine, that's the first time I've studied homeopathy, officially starting in 2007."

(P11, male, 39 years old, preacher) Perspective of the patient the Ahmadiyya chose homeopathy as their primary treatment because since childhood they have known and been familiar with the socialization of homeopathy.

"Usually this is the medicine, for this, but I don't know, the language is difficult. So I don't know, when it's explained, yes it is."

(P15, female, 45 years old, Ahmadiyah patient, selfemployed). Meanwhile, non-Ahmadiyya patients choose homeopathic treatment because they have the hope of healing, without side effects and free of charge. The implementation of informed consent homeopathic in the Ahmadiyya congregation generally uses informed consent oral.

"Yes, Mr. Mubalig is here, visit here. I can't walk, Mr. Mubalig who visited here, then asked Mrs. how did it change? It's fine, sir, but I asked for (homeopathic medicine) before drinking, I was told to fast first, one hour, after drinking I also fast for one hour". (P19, female, 55 years old, non-Ahmadiyya patient, farmer).

\section{Homeopathic Services in General by Practitioners of the Ahmadiyya}

Homeopathic services are health services that are jointly organized within the organization of the Ahmadiyya congregation with the main objective of serving humanity (humanity first) and aid for common illnesses. In homeopathy there are no special procedures such as conventional medical treatment such as patient registration and medical procedures or interventions, especially invasive procedures. The flow in homeopathic medicine is that the patient comes to the dispensary (medicine house) homeopathy, either at the branch or at the center. The patient comes with his will 
and consciousness to ask for homeopathic remedies.

Firstly, practitioners ask the symptoms and complaints patient's holistically so that usually the anamnesis takes the longest time. Furthermore, practitioners with medical backgrounds will provide a diagnosis or patient's illness, while non-medical practitioners will usually only ask about the patient's symptoms and complaints without diagnosing the disease then the practitioner will make and mix homeopathic medicines according to the symptoms or complaints.

Practitioners present alternative courses of action if homeopathic remedies cannot help treat the patient. Generally, medical practitioners will refer to doctor specialist, while non- medical practitioners will advise patients to go to the hospital. In conveying the patient's prognosis, the practitioner usually knows that the patient's prognosis will be good or not, and this homeopathic remedy can help the patient, but if the disease is chronic, the patient will be advised to conventional medical treatment. Financing in homeopathic medicine is generally free. However, practitioners who have independent homeopathic clinics have set certain rates for drugs and consultations.

\section{Implementation of the method and content of informed consent in homeopathic services: Practitioner's Perspective}

This study found that the application of the method and content of informed consent for medical and non-medical personnel is the same as Indonesia Minister of Health Regulation No. 290/2008 regarding how a practitioner, especially medical personnel, applies the method and content of informed consent. Homeopathic treatment services in the Ahmadiyya are basically health activities whose purpose is to provide first aid, assist healing and improve the quality of life of members of the Ahmadiyya so that informed consent is used orally, while for non-Ahmadiyya, informed consent written is required provided by the National Homeopathy Department.

"...I was wondering if there were any complaints, how long has it been, because I'm basically a doctor, so I asked what the symptoms were, then it seems like it can be done with homeopathy or not, if not I say it's homeopathy just to help, but I think you have to go to the doctor, go to the hospital, because the consultation is so tough." (P03, female, 46 years old, doctor).

The flow of homeopathic treatment services by medical and non-medical practitioners is almost the same; there are only differences in the diagnosis and patient prognosis. For practitioners of medical personnel and non-medical personnel, both will ask each patient's symptoms and complaints and then for medical personnel practitioners will explain and disclose the patient's disease or diagnosis. Furthermore, the practitioner explained that if later there was aggravation, which is a reaction that occurs due to consuming homeopathy with certain potency (dose), the patient can return to the consultation again.

Homeopathic medicines are presented in the form of globules (lactose sugar) which are dripped with solution mother tincture (extraction from plants, animals or minerals) and types of external ointments, and there is no invasive action. In conveying the patient's prognosis, the medical practitioner will usually know whether the patient's illness is acute or not. If the disease is acute, then the prognosis will be good after using homeopathy but if the disease is chronic, then the practitioner will suggest seeking conventional medical treatment. However, for non-medical practitioners, if they find a patient with a chronic illness, they will advise the patient for treatment at the hospital.

"...if the disease is acute and the prognosis is good, we will just tell you. Homeopathic medicine can help, but if within a certain period of time it doesn't, then you have to find another way or it gets worse than homeopathy can't help anymore." (P03, female, 46 years old, doctor).

Funding for homeopathic remedies is generally free, but for Ahmadiyya congregation patients there is a sacrificial fee called 'candah', which is a membership fee ranging from $1 / 16$ to $1 / 10$.

"Well, this is it. This may be a bit different from my other colleagues. Because in me, this is a practice, yes, and there is a permit, there is legality... Now for financing, there is indeed some kind of service from the service, we have to determine the minimum and maximum. For treatment at my clinic, the minimum medicine is IDR 25,000, the maximum is around IDR 30,000 to IDR 50,000 for the public, yes, but there is also for members, but it doesn't matter as long as it doesn't cost anything." (P05, male, 43 years old, Independent Homeopathic Clinic)

Practitioners who have independent homeopathic clinic usually have set a certain standard of fees for medicines and homeopathic treatment consultations. Homeopathic independent clinics also adjust to patients who come, practitioners will first see the patient's needs and patient background such as age and occupation so that it is not evenly distributed all patients have to pay, especially consulting services. The practitioner will not provide a consultation fee so the patient only pays for the homeopathic medicine. In other words, the practitioner will see a patient feel comfortable, happy not add to the patient's burden. 


\section{Implementation of the Method and Content of Informed Consent in Homeopathic Services: Patient Perception}

The results of this study found that patients of the Ahmadiyya have known homeopathy since childhood, while non-Ahmadiyya patients generally know homeopathic treatment by word of mouth. The important elements in this study were found that patients or guardians who came to homeopathic services must be competent, willing, providing information, making decisions on plans, and authorizing.

The first element is competent, for example, Ahmadiyya patients who have known homeopathy since childhood and ask for medicine. to practitioners or preachers.

"Once, when you weren't feeling well and couldn't leave the house, you just asked my mother to contact the preacher. I said the characteristics are the same as the mother and the preacher who came to my house."

\section{(P17, male, 18 years old, Ahmadiyya patient, student)}

In another study, a non-Ahmadiyya patient experienced narrowing of the kidney tract and swelling of kidney stones accompanied by pain in all muscles. The patient has had multiple surgeries and outpatient treatment at the hospital, but his illness has not yet recovered. The patient finds it difficult to walk with a weak physical condition and is accompanied by his wife so that the one who can give consent is his wife by still asking the patient.

"Yes, Mr. Mubalig explained everything. The medicine is this, for this it is explained. For example, if you have a history of illness, you will be asked what it is, and then you will be given medication". (P18, male, 38 years old, non-Ahmadiyya patient, and self- employed).

The second element is willingness, as a prerequisite for the approval of medical treatment to be valid. It is found in the study that if homeopathic remedies cannot help treat the patient, the practitioner will refer him to the hospital but if the patient still decides to choose homeopathic treatment, the practitioner can still treat the patient's symptoms and complaints by giving informed consent written.

\section{Implementation of the Method and Content of Informed Consent in Homeopathic Services: Management Perspective National Homeopathy Department (DHN)}

The National Homeopathy Department was established in 1997, but since 1996 members of the Ahmadiyya have started to help, sorting out homeopathic medicines where every year the Ahmadiyya held an annual meeting and the caliph of the Ahmadiyya congregation who was in Indonesia provided homeopathic kits to be managed by the Ahmadiyya in Indonesia. The goal is that all members of the Indonesian Ahmadiyya congregation can feel the benefits of homeopathy as first aid and be given if they have complaints or symptoms before consulting a doctor or health facility. Furthermore, National Homeopathy Department (DHN) established a dispensary homeopathic (house of medicine) in branches throughout Indonesia which was held by PJH (the person in charge of homeopathy) and DHN's duties were to distribute homeopathic medicines to all these branches, to provide education to preachers and members of the Ahmadiyya who could perform homeopathic services. In this study, DHN also explained the effectiveness of homeopathic remedies that actually homeopathy treats symptoms of common illnesses.

"...so far there have been no problems, yes, all patients who seek treatment, all people who need homeopathic medicines, if at the beginning the symptoms of complaints are given with drugs that match their complaints, they usually subside by themselves." (P08, female, 48 years old, secretary of DHN)

The symptoms that the patient complains about are those treated by homeopathy, but when the symptoms spread, DHN asks the practitioner to consult the DHN team first. DHN's task is not only to distribute drugs to the branches of the Ahmadiyya congregation throughout Indonesia but also to have records on patient status consisting of name, age, gender, patient address, patient complaints, what homeopathic medicines were given and medical records. DHN also stated that the application of informed consent homeopathic in the field mostly uses verbal consent.

"If there are some who already understand homeopathy, there is no need to explain, but once there are those who do not understand, we will explain. Because for our safety we also go out (non-Ahmadiyya), but if we go inside (internal Ahmadiyya) it remains as our data record that if needed we already have informed consent." (P08, female, 48 years old, secretary of DHN)

In homeopathic medicine itself, there are no medical procedures such as surgery, invasive procedures, but only the administration of homeopathic medicines such as oral medicines and ointments. However, DHN requested that practitioners continue to explain homeopathy to patients, especially non-Ahmadiyya with several considerations such as benefits and side effects. If the patient and/or guardian have agreed, then they are then asked to sign that the patient receives this homeopathic remedy openly and will not be present in advance which can harm both parties. 


\section{The Importance of Informed consent and the Elements of Informed Consent in Homeopathic Services by Practitioners of the Ahmadiyya}

First, the purpose of having informed consent in homeopathic treatment by the Ahmadiyya is to respecthuman dignity. Therefore, the Ahmadiyya makes homeopathic medicine a humanitarian mission, without compensation and to respect the dignity of human beings who are free and autonomous to have the right to choose what type of treatment services will be used or not used by patients. Second, informed consent aims to avoid fraud and coercion of the Ahmadiyya congregation in Indonesia which until now is still underestimated by some Indonesian people, therefore homeopathic treatment is needed, so an informed consent form is needed, especially for non-Ahmadiyya patients. Third, legalizing homeopathic treatment services even though there is an independent Indonesian Homeopathic Association whose members are both doctors and non-doctors and not on behalf of the Ahmadiyya. Therefore, the need for informed consent is not only given enough information so that patients understand, but can work together with doctors or homeopathic practitioners better for the patient's healing process.

The results of the study found that the homeopathic practitioner of the Ahmadiyya had elements such as good qualities in revealing the disease or diagnosis of the patient, then after explaining the diagnosis of the disease. Then explain the purpose of the action by disclosing the correct and complete content of homeopathic information such as the procedure for taking the drug and the possible reactions it may cause. Non-medical practitioners also offer appropriate medical intervention or treatment plans and solutions if homeopathic remedies cannot help treat the patient's illness. Therefore, the information provided must be good, correct and complete.

\section{Conclusion}

1. Understanding and application of informed consent the same between medical practitioners and non-medical personnel by using informed consent oral for patients of the Ahmadiyya congregation and informed consent written for patients of non-Ahmadiyya congregations as an effort to obtain evidence of approval that can document legal and ethical accountability.

2. Informed consent used on behalf of the group or what is called 'kinship autonomy' is informed consent given to a person, but by several parties at once in the family such as from husband/wife, uncle, in-laws and so on.

3. In this study, it was found that homeopathic medicine can be a primary treatment for patients of the Ahmadiyya congregation, complementary medicine for patients undergoing treatment concurrently with conventional medical treatment, and alternative medicine for patients who are dissatisfied with conventional medical treatment, thus making homeopathy an alternative medicine.

4. The elements of informed consent achieved were good, such as:

- A good way of delivering it.

- Correct in conveying the content of homeopathic information (diagnosis, goals, alternative actions, risks, patient prognosis where practitioners never promise a cure and generally free financing, except for practitioners who open independent homeopathic clinics.

5. Factors that influence patients in choosing homeopathic treatment:

- Dissatisfaction, namely patients are not satisfied with conventional medical treatment, namely $34 \%$ of patients.

- Need for personal control, namely patients seeking alternative therapy because they prioritize personal autonomy, namely $16 \%$ of patients.

- Philosophical congruence, namely therapy the alternative is more attractive because it is considered more in line with the patient's values, spiritual/religious philosophy or beliefs about the meaning of health from a disease, which is $50 \%$ of patients

\section{Recommendations}

1. Researcher recommends the management and leaders of the Homeopathy Department National (DHN) to provide more comprehensive education by making policies and outreach about ng informed consent to medical practitioners and in particular to non-medical personnel such as preachers or members of the Ahmadiyya congregation who attend homeopathy training.

2. The researcher hopes that there are clear rules and regulations, especially regarding informed consent in the Law on Complementary Alternative Medicine Services as well as in Law Number 29 of 2004 concerning Medical Practice which contains informed consent clear and complete.

3. Homeopathy is still very little known by the people of Indonesia even though the potential for developing homeopathy is very wide so that it can be produced domestically. Therefore, there must be clear, legal and legal regulations.

4. Homeopathy is not only a science but can be pursued to achieve a progress such as conventional medical treatment to conduct international cooperation with several countries. 


\section{References}

1. Nasichin M (2017) Implementation of informed consent between the Muhammadiyah Gresik Hospital and caesarean section patients based on Article 45 of Law No. 29 of 2004 concerning medical practice. Pro Law Journal 6(1): 1-7.

2. Titisari NW (2008) Implementation of approval for medical action in protecting Askesin patients at RSU RA Kartini, Jepara Regency. Thesis, Semarang.

3. Ratman D (2009) Medical Law (Text, Cases, and Materials), $2^{\text {nd }}($ Edn.), United Kingdom: Oxford University.

4. Kusmaryanto CB (2015) Bivatika. Jakarta: Kompas.

5. Beauchamp TL, Childress JF (2019) The Principle of Biomedical Ethics, $8^{\text {th }}$ (Edn.), New York: Oxford University Press.

6. Odette P (2012) Complementary and alternative medicine-facts and figures (Part II). Malta College of Family Doctors 1(2): 17-27.

7. Pal SK (2002) Complementary and alternative medicine: An overview. Current Science 82(5): 518-524.
8. (2009) Traditional medicine. World Health Organization, pp: 1-4.

9. Rachma E (2018) Homeopathic therapy controversy to cure various diseases. Pharmacy Magazine 3(1): 12-15.

10. Setiawan L (2005) Study on the Development of Knowledge Management of Traditional Medicine through the Role of the Center for Development and Application of Traditional Medicine (SP3T) of West Java Province. Thesis, Bandung.

11. Ahmad HMBM (1989) Da'watul Amir. Peace House Foundation.

12. Suryawan MA (2004) Not Just Black and White: An Explanation of the Objections and Accusations Frequently Asked Against the Ahmadiyya Congregation. Jakarta.

13. Santoso I (2020) The Resilience of the Indonesian Ahmadiyya Congregation (JAI) in Responding to Religious Social Discrimination (Central Jakarta Study of the Ahmadiyya Congregation). Thesis, UIN Jakarta. 